\title{
Ecologia da interação entre as pequenas flores de quilha de Stylosanthes viscosa Sw. (Faboideae) e as grandes abelhas Xylocopa (Neoxylocopa) cearensis Ducke, 1910 (Apoidea, Hymenoptera), em duna tropical
}

\author{
Mauro Ramalho' \& Jaqueline Figuerêdo Rosa ${ }^{1,2,3}$ \\ ${ }^{1}$ Laboratório de Ecologia da Polinização - ECOPOL, Instituto de Biologia, \\ Universidade Federal da Bahia - UFBA, Rua Barão de Jeremoabo, s/n, Ondina, \\ CEP 40170115, Salvador, BA, Brasil \\ ${ }_{2}^{2}$ Instituto Federal de Educação, Ciência e Tecnologia Baiano, Campus Guanambi, \\ Distrito de Ceraíma, CP 09, CEP 46430-000, Guanambi, BA, Brasil \\ ${ }^{3}$ Autor para correspondência: Jaqueline Figuerêdo Rosa, e-mail: jaquefrosa@gmail.com, jarosa@ufba.br
}

\begin{abstract}
RAMALHO, M. \& ROSA, J.F. Ecological interaction between the tiny keel flowers of Stylosanthes viscosa Sw. (Faboideae) and the large bee Xylocopa (Neoxylocopa) cearensis Ducke, 1910 (Apoidea, Hymenoptera), in tropical sand dune. Biota Neotrop. 10(3): http://www.biotaneotropica.org.br/v10n3/en/ abstract?article+bn01810032010.
\end{abstract}

\begin{abstract}
Stylosanthes viscosa is a common 'herb' in the tropical sand dunes of the Brazilian coast with clumped distribution in urban sand dunes of Salvador, BA. Its tiny keel flower with a very small amount of nectar hidden inside the corolla tube, a single open flower/inflorescence/day and the low floral density altogether should not be attractive to large bees. This should be true mainly upon the high-demanded energy for thermoregulation within the tropical sand dunes. Contrary to this expectation, most of the bee species sampled on S. viscosa flowers were medium to large sized bees and harvested nectar in legitimate visits by activating the keel's pollination mechanism of flowers. However, the keel was always inactivated after being visited by the enormous and frequent (78\%) Xylocopa bees. All the flowers visited by these bees (including those with inactivated keels), and those experimentally protected from bee visiting produced fruits (100\%). The specialized embolus mechanism of the anthers assures self-pollination. Because of this autonomous self-pollination and self-compatibility it was not possible to discriminate the relative importance of both facilitated self-pollination and cross-pollination by bees. Nevertheless, the large Xylocopa bees didn't limit self-pollination. Xylocopa cearensis was the most abundant bee $(63 \%)$ and it visited several flowers $(13.0 \pm 4.27)$ in each flight route in the same clump, in spite of the low floral density therein ( 5 to 20 flowers. $\mathrm{m}^{-2}$ ). Flight distances between successive flowers varied between one and two meters (49\%), and so they were higher than would be possible (15 to $70 \mathrm{~cm}$ ) given the floral density in the clumps. The flight routes were directional, and most of shifting direction between successive flowers was below $90^{\circ}$ with high frequency of small angles $\left(<30^{\circ}\right)$. This general pattern is explained by foraging optimization with adjustments to critical resource level thresholds. Paradoxically, floral biology and flowering pattern of $S$. viscosa should discourage the largest dune dweller bees, but this strategy works just temporarily. In this melittophilous species, the autonomous self-pollination (assured by the embolus) can be better explained by the automatic selection hypothesis rather than by reproductive assurance hypothesis, considering the availability of large bee pollinators in the tropical dunes.

Keywords: automatic selection hypothesis, fight pattern, reproductive assurance hypothesis.
\end{abstract}

RAMALHO, M. \& ROSA, J.F. Ecologia da interação entre as pequenas flores de quilha de Stylosanthes viscosa Sw. (Faboideae) e as grandes abelhas Xylocopa (Neoxylocopa) cearensis Ducke, 1910 (Apoidea, Hymenoptera), em duna tropical. Biota Neotrop. 10(3): http://www.biotaneotropica.org.br/v10n3/pt/ abstract?article+bn01810032010.

Resumo: Stylosanthes viscosa é uma herbácea comum nas dunas tropicais da costa brasileira, com distribuição agregada nas dunas urbanas de Salvador, BA. Suas flores de quilha diminutas, com uma pequena quantidade de néctar escondido no tubo da corola, a abertura de uma única flor/inflorescência/dia e a baixa densidade floral, juntos, não deveriam ser atrativos para as abelhas de grande porte. Isso deve ser verdadeiro, principalmente, sob a alta demanda energética para termorregulação em dunas tropicais. Ao contrário do esperado, a grande maioria das espécies de abelhas amostradas nas flores de $S$. viscosa tem tamanho médio a grande e coletou néctar em visitas legítimas, acionando o mecanismo de polinização da quilha. Entretanto, a quilha sempre ficava inutilizada após as visitas das grandes e frequentes (78\%) abelhas Xylocopa. Todas as flores visitadas por essas abelhas (inclusive aquelas com a quilha inutilizada) e as protegidas experimentalmente das visitas das abelhas produziram frutos regularmente (100\%). O mecanismo de êmbolo das anteras assegura a autopolinização. Como há autopolinização autônoma e o sistema é autocompatível ainda não foi possível discriminar a importância relativa da autopolinização facilitada e da polinização cruzada por abelhas. Entretanto, as grandes abelhas Xylocopa 
Ramalho, M. \& Rosa, J.F

não limitam a autopolinização. Xylocopa cearensis foi a abelha mais abundante (63\%) e visitou várias flores $(13,0 \pm 4,27)$ em cada rota de vôo, numa mesma mancha, apesar da baixa densidade floral (5 a 20 flores. $\left.\mathrm{m}^{-2}\right)$. A distância de vôo entre flores sucessivas variou entre um e dois metros (49\%), acima do que seria possível $(15 \mathrm{a} 70 \mathrm{~cm}$ ) dada a densidade floral nas manchas. As rotas de vôo foram direcionais, isto é, a maioria dos ângulos de mudança de direção entre flores sucessivas foram abaixo de $90^{\circ}$, com alta frequência de ângulos pequenos $\left(<30^{\circ}\right)$. Este padrão geral é explicado com a otimização de forrageio, com ajuste a limiares críticos de oferta de recursos. Paradoxalmente, a biologia floral e o padrão de florescimento de $S$. viscosa deveriam desestimular a visita dessas grandes abelhas, mas esta estratégia funciona apenas temporariamente. Nesta espécie melitófila, a autopolinização autônoma (assegurada pelo êmbolo) pode ser melhor explicada pela hipótese de seleção automática do que pela hipótese de segurança, considerando a disponibilidade de abelhas grandes como polinizadores nas dunas tropicais.

Palavras-chave: hipótese da seleção automática, padrão de vôo, hipótese da segurança reprodutiva.

\section{Introdução}

A evolução da flor de quilha foi desencadeada pelos Hymenoptera, em particular as abelhas, ainda que em alguns poucos casos se observe a associação desse tipo de flor com beija-flores e morcegos (Endress 1994). Essas flores têm arquitetura muito elaborada e integrada, envolvendo a corola, estames e estilete ('synorganization'), que resulta num mecanismo versátil e preciso de deposição de pólen sobre o corpo dos polinizadores. Provavelmente, também constitui um dos casos mais bem sucedidos de proteção do pólen contra o forrageio ativo pelas abelhas (Westerkamp 1996) que, salvo raras exceções, são consumidores totalmente dependentes desta fonte de proteína. $\mathrm{Na}$ busca do néctar protegido no fundo da corola dessas flores, as abelhas acionam a quilha, fazendo com que uma pequena carga de pólen seja depositada sobre um ponto restrito do seu corpo, de maneira imperceptível e/ou pouco acessível. Assim, a pequena quantidade de pólen produzida tem mais chances de ser transferida para outra flor do que ser coletada e consumida pela própria abelha.

O gênero Stylosanthes Sw. (Faboideae) reúne plantas herbáceas ou sub-arbustos com flores de quilha, nativas dos trópicos e sub-trópicos das Américas, África e Ásia (Sawkins et al. 2001). Das 30 a 45 espécies reconhecidas (dependendo do tratamento; p.ex., Stappen et al. 2002), cerca de 25 ocorrem no Brasil, que também se destaca como principal centro de dispersão do gênero. Stylosanthes viscosa Sw. (Faboideae) está amplamente distribuída na América tropical, desde o Brasil até o México (Sawkins et al. 2001), incluindo regiões áridas e semi-áridas, restingas e dunas costeiras. $\mathrm{O}$ gênero, em particular $S$. viscosa, diferencia-se pelas flores de tamanho muito reduzido (estandarte com cerca de 4,0 $\mathrm{mm}$ de comprimento) e pela floração relativamente longa, porém com baixa quantidade de flores abertas por planta/dia.

As flores de quilha de Faboideae com frequência se inserem no "sistema de polinização por abelhas grandes", na classificação de Frankie et al. (1983), em que se destacam pelo tamanho corporal as abelhas do gênero Xylocopa Latreille, 1802. As abelhas Xylocopa têm distribuição pantropical (Hurd \& Moure 1963, Gerling et al. 1989, Minckley 1998) e são abundantes nas dunas e restingas com vegetação aberta na costa tropical do Brasil (Gottsberger et al. 1988, Silva \& Martins 1999, Viana et al. 2002, Viana \& Kleinert 2006). Particularizam-se pela associação frequente com plantas de floração prolongada do tipo "steady state", com flores relativamente grandes, de arquitetura robusta e néctar protegido (Endress 1994), porém se comportam como forrageadores oportunistas (Frankie et al. 1983). Também se diferenciam pela habilidade de vôo a longas distâncias, que podem assegurar a polinização cruzada de plantas muito espaçadas ('trapliner'; van der Pijl 1954, Janzen 1983).

Observações prévias em ambientes de dunas costeiras tropicais no Brasil indicam visitas frequentes de abelhas Xylocopa às flores de S. viscosa (Gottsberger et al. 1988, Viana et al. 2002, Viana \&
Kleinert 2006). Embora sem registros extensivos, essa interação não deve ser contingente, dada a ampla sobreposição geográfica e ecológica de ambos os grupos. Em contrapartida, o forte contraste de tamanhos sugere inadequação morfológica e funcional. Por um lado, isto poderia levar à baixa eficiência de polinização da flor: a redução extrema da flor de quilha parece paradoxal, pois as abelhas precisam ser relativamente robustas para serem capazes de movimentar esse aparato integrado e promover a polinização. Por outro lado, o tamanho da flor de $S$. viscosa, a oferta reduzida de néctar e a aparente baixa densidade floral poderiam levar à perda de eficiência de forrageio pelas abelhas de grande porte. A teoria sobre a otimização do forrageio pressupõe que a busca e escolha de fontes alimentares envolvem decisões de custo-benefício que afetam o valor adaptativo (Pyke 1984). Isto leva à premissa geral de que os animais seriam modelados para fazer as melhores escolhas possíveis, ajustando-se às flutuações na oferta de alimento. Como a "melhor escolha" também depende de restrições fisiológicas e comportamentais, indivíduos ou espécies podem apresentar ajustes diferentes para otimizar o forrageio num mesmo recurso, sob as mesmas condições de oferta. Várias abelhas se mostraram muito adequadas aos estudos experimentais sobre eficiência de forrageio (p.ex., Waddington 1980, Seeley 1995, Nuñez 2000).

Em estudos regionais comparativos sobre rotas de vôo com Xylocopa, foi possível constatar variações nas estratégias de forrageio entre espécies (Jacobi et al. 2005) e de uma mesma espécie sob condições variáveis de oferta de uma mesma fonte floral (Costa et al. 2002, Pigozzo et al. 2007). Neste tipo de abordagem são previstos ajustes nas distâncias e/ou na direção de vôo em função da distribuição e variação espacial na oferta de recursos (p.ex., néctar), de acordo com premissas vinculadas à teoria geral de forrageio ótimo (Schoener 1971, Waddington 1980, Pyke 1984). Entretanto, os mecanismos associados ao padrão de forrageio podem ser bastante complexos, por um lado, envolvendo restrições fisiológicas, aprendizagem, sensibilidade à média ou variância de oferta do recurso floral, tendência a maximizar a energia obtida ou a minimizar o tempo gasto com sua obtenção; e, por outro lado, as restrições do ambiente e do recurso (p.ex. morfologia floral) (Waddington 1980, Pyke 1984).

Neste estudo, foram avaliadas as interações entre as pequenas flores de quilha de S. viscosa e as grandes abelhas Xylocopa, no hábitat de dunas tropicais. Para analisar os efeitos dos dois lados da relação ecológica, foram caracterizados os sistemas de polinização e reprodutivo da planta, a frequência e o comportamento dos seus principais visitantes florais. Como as flores de S. viscosa são hermafroditas, a expectativa era de que apresentassem polinização cruzada, investindo, por exemplo, na auto-incompatibilidade, se confirmada a associação ecológica dominante com abelhas robustas de alta mobilidade. O sistema reprodutivo também será analisado à 
luz da hipótese de segurança reprodutiva, que neste caso, envolve a oferta de abelhas de grande porte nas dunas e seu papel na polinização (polinização cruzada versus autopolinização) dessas pequenas flores de quilha. Dadas as restrições aparentes de forrageio por néctar nas flores pequenas, com baixa densidade/planta/área, detalhou-se o padrão de movimento de Xylocopa (Neoxylocopa) cearensis Ducke, 1910. Neste caso foram analisadas rotas de vôo e sua relação com a densidade de flores nos agregados, para verificar se as respostas dessas grandes abelhas eram compatíveis com a teoria geral de otimização (Pyke 1984). A ausência de padrão de vôo (distância e direção) indicaria que a abelha não estaria sendo capaz de fazer ajustes compatíveis com a oferta de néctar, com perda de eficiência de forrageio. Também era de se esperar mudanças no padrão de vôo com variações na densidade de flores/dia durante a floração, em caso de otimização do forrageio.

\section{Material e Métodos}

Stylosanthes viscosa Sw. é uma herbácea ou sub-arbusto prostrado (definição que varia de acordo com o autor), perene com ampla distribuição nas Américas, onde ocupa grande variedade de ambientes, dos trópicos úmidos aos trópicos áridos (Sawkins et al. 2001), sendo bastante abundante nas restingas e dunas costeiras do Brasil (Viana et al. 2006, Sacramento et al. 2007). Apresenta floração ao longo do ano, com picos entre julho e janeiro (Viana et al. 2006). Tem grande potencial de uso agronômico para melhoria da qualidade de solos, principalmente nas regiões tropicais secas, podendo ser usada como forrageira ou adubo verde (Barros et al. 2005, Alcântara et al. 2007, Pereira 2008).

Os experimentos sobre o sistema reprodutivo de $S$. viscosa, as observações do comportamento dos seus visitantes florais, incluindo os registros das rotas de vôo de Xylocopa (Neoxylocopa) cearensis Ducke, 1910 , foram realizados em um pequeno remanescente de dunas (12 $59^{\prime} 15.51^{\prime}$ 'S e $38^{\circ} 26^{\prime} 32.71$ " W), na área urbana de Salvador, na Bahia. Apesar de pequenas e isoladas, essas dunas apresentam a flora típica e nativa da região costeira. Além de Stylosanthes Sw., no estrato herbáceo-sub-arbustivo são particularmente comuns espécies de Arrabidaea DC., Borreria G.Mey., Cuphea P.Browne, Centrosema Benth., Cassia L., Eriope Humb. \& Bonpl., Ipomoea L., Waltheria L. Nas dunas estudadas, $S$. viscosa tem distribuição agregada, ocorrendo em grandes manchas discretas nas áreas abertas, sob forte insolação direta. Essa condição permite ampla visualização e facilita o acompanhamento do movimento de vôo dos forrageadores em cada mancha. Para detalhamento da biologia floral, flores foram colhidas a cada hora no campus de Ondina da Universidade Federal da Bahia (UFBA) entre 06:00 e 13:00 horas, imediatamente, dissecadas e analisadas ao estéreo-microscópio, no Laboratório de Ecologia da Polinização (ECOPOL) da UFBA.

Para a caracterização do sistema reprodutivo de $S$. viscosa e da influência das visitas de $X$. cearensis sobre a produção de sementes, 10 flores foram ensacadas ainda em botão e 10 flores foram ensacadas após a primeira visita das abelhas, nos dias 20, 24 e 26 de agosto de 2004 e 04 de setembro de 2004. Após dois meses foi registrada a produção de sementes.

As informações sobre os visitantes florais de Stylosanthes foram obtidas nas dunas, entre agosto e novembro de 2004. Para estimar a frequência, as abelhas foram amostradas com rede entomológica, durante 15 minutos a cada hora, entre 08:00 e 13:00 horas, pois esse foi o período em que as flores estavam abertas e receptivas. Os espécimes coletados foram identificados ao estéreo-microscópio e depositados na coleção científica do ECOPOL-UFBA. No período entre as coletas, registrou-se o comportamento das abelhas nas flores (cerca de 360 horas de observação).

Foram feitos registros detalhados de rotas de vôo de $X$. cearensis, a espécie mais abundante e frequente nas flores de $S$. viscosa. Sete indivíduos foram acompanhados (visualmente e seguidos) desde o momento que chegavam à mancha até a saída. Imediatamente após a visita, cada flor foi marcada com etiquetas numeradas, para sequenciamento das flores visitadas. Após o término de cada rota de vôo, foram medidos as distâncias e os ângulos de deslocamento entre flores com números sucessivos. Quatro rotas foram registradas num período de alta densidade de flores ( 21 flores. $\mathrm{m}^{-2}$ ) e três num período de baixa densidade de flores ( 5 flores. $\mathrm{m}^{-2}$ ), respectivamente em 01/09 e 09/09/2004. Para confirmar se haviam diferenças estatísticas nas densidades florais entre os dias 01/09 e 09/09/2004, as densidades foram estimadas em transecções ao acaso de $2 \mathrm{~m}$ de largura por $5 \mathrm{~m}$ de comprimento, traçadas sobre as manchas floridas de S. viscosa, onde também foram feitos os registros das rotas de vôo, e foi usada a ANOVA para testar a hipótese nula de que não houve diferenças significativas nas densidades florais médias entre os dois dias.

Também foi usada a ANOVA para testar a hipótese nula de que não houve diferenças significativas nas distâncias e nos ângulos médios das rotas de vôo das abelhas. Para testar as hipóteses nulas de que não houve diferenças nas distâncias médias de vôo entre flores e de que não houve diferenças nos desvios padrões das rotas entre os dias de maior e menor densidade foi usado um teste de Mann-Whitney (uma vez que os dados não se enquadraram às premissas de normalidade e homocedasticidade requeridos pela ANOVA). Foram usados os programas estatísticos SPSS 13.0 for Windows e GraphPad Instat 3.05 e foi adotado o nível de significância de 0,05 .

\section{Resultados}

\section{Biologia floral e sistema reprodutivo}

As flores de Stylosanthes viscosa Sw. são zigomorfas e hermafroditas, apresentam coloração amarela e estão dispostas em inflorescências. A flor é muito pequena, sendo que a corola apresenta comprimento médio de 4,26 $\pm 0,30 \mathrm{~mm}(\mathrm{~N}=5)$. Das cinco pétalas que formam a corola, o estandarte é a maior, e tem em média 4,66 $\pm 0,41 \mathrm{~mm}$ de comprimento $(\mathrm{N}=5)$ e em média $5,94 \pm 0,48 \mathrm{~mm}$ de largura $(\mathrm{N}=5)$. O estandarte, ala e carena são unguiculados. Cada pétala da quilha se dobra na ponta, formando um tubo aberto na extremidade, por onde se projetam as anteras e o estigma, quando o mecanismo é acionado pelo visitante. As alas apresentam, no lado interno, projeções (em forma de "gancho") que se encaixam em dobras (em forma de "bolsa") do lado externo da pétala da quilha. Quando a ala é pressionada para baixo pelo visitante, as pétalas da quilha se movem junto e expõem as anteras e o estigma. As pétalas da quilha e as alas também têm dobras posteriores que se articulam com dobramentos da pétala estandarte, permitindo a volta da estrutura à posição inicial, quando o visitante deixa a flor. O gineceu tem comprimento médio de 3,82 $\pm 0,81 \mathrm{~mm}(\mathrm{~N}=5)$, o estigma é puntiforme e o ovário longo e semi-ínfero.

$\mathrm{O}$ androceu é composto por dez estames concrescidos na base (monadelfo), formando um tubo por onde passa o estilete, com o estigma emergindo acima das anteras. Existem dois tipos de estames: cinco com anteras pequenas, arredondadas, dorsifixas, que não produzem pólen, e outros cinco com anteras maiores, elípticas e alongadas, basifixas, que produzem pólen e têm deiscência longitudinal. Nos botões jovens, poucas horas antes da flor abrir, os estames com anteras arredondadas estão abaixo dos estames das anteras elípticas com pólen. Quando o botão está prestes a abrir (por volta das 07:00 horas da manhã), as anteras arredondadas já estão posicionadas acima das anteras elípticas, pois seus filetes se alongam fazendo com que removam o pólen das anteras elípticas. Assim, quando a quilha é acionada, são as anteras arredondadas e estéreis que expõem o pólen. 
Por volta das 08:00 horas da manhã, as flores começam a abrir, já com pólen e néctar disponíveis. Ao redor das 13:30 horas as flores começam a murchar. Normalmente, abre apenas uma flor por dia, por inflorescência. Em cada inflorescência do tipo espiga, com 1,0 a 2,0 cm de comprimento, são observados botões e frutos em vários estágios de desenvolvimento, protegidos por muitas brácteas.

Os espécimes de Stylosanthes viscosa tem distribuição agregada, formando manchas discretas nas áreas mais abertas das dunas. Devido ao porte muito baixo $(<0,5 \mathrm{~m})$, as flores espaçadas têm distribuição praticamente bidimensional nas manchas. Aliada ao padrão diário de abertura, a densidade de flores nas manchas é muito baixa e muito variável: num intervalo de uma semana, variou entre o valor mínino de cinco flores.m ${ }^{-2}(09 / 09 / 2004)$ e máximo de 21 flores.m ${ }^{-2}$ (01/09/2004). Considerando o tamanho diminuto da flor e a baixa densidade de flores, o pólen e o néctar estão bastante pulverizados na área total de cada mancha florida.

Todas as flores marcadas, ensacadas e não ensacadas produziram frutos e sementes. Provavelmente, nas flores não visitadas houve autopolinização autônoma, embora não possa ser descartada a possibilidade de agamospermia uma vez que não foram realizados experimentos de emasculação das anteras. Naquelas flores visitadas pelas abelhas pode ter havido autopolinização autônoma, autopolinização facilitada e polinização cruzada, sendo o sistema auto-compatível.

\section{Sistema polinizador: conjunto de visitantes ou polinizadores}

As flores de $S$. viscosa foram visitadas por 10 espécies de abelhas (Apoidea), de cinco gêneros e, muito esporadicamente, por uma pequena mariposa (Lepidoptera), todas em busca de néctar. Frequentemente, as abelhas iniciavam as visitas por volta de 08:30 horas, logo após a abertura das flores, com pouca variação na taxa de visitação ao longo da manhã. Durante esse período o pólen está disponível para a polinização e o estigma receptivo.

Entre as abelhas (Figura 1), foram registradas três espécies de Centris Fabricius, 1804 [Centris (Hemisiella) tarsata Smith, 1874; Centris (Hemisiella) trigonoides Lepeletier, 1841; Centris (Centris) spilopoda Moure, 1969], duas espécies de Exomalopsis Spinola, 1853 [Exomalopsis sp.1 e Exomalopsis (Exomalopsis) analis Spinola, 1853], uma espécie, não identificada, de Dicranthidium Moure \& Urban, 1975, duas espécies, não identificadas, de Megachile Latreille, 1802 e duas espécies de Xylocopa Latreille, 1802 [Xylocopa (Neoxylocopa) cearensis Ducke, 1910; Xylocopa (Schonnherria) subcyanea Pérez, 1901]. A maioria dessas abelhas pode ser considerada robusta e as espécies de Xylocopa estão entre as maiores abelhas. As abelhas Xylocopa foram mais frequentes nas flores $(77,7 \%)$, em particular, $X$. cearensis $(63,4 \%)$. As demais espécies apresentaram, isoladamente, abundância baixa e similar entre si (Figura 1).

Registrou-se uma inversão temporal na abundância relativa dos grupos dos visitantes ao longo da floração de $S$. viscosa: entre agosto e setembro, as abelhas Xylocopa foram dominantes e praticamente os únicos visitantes, enquanto, em outubro e novembro, a sua abundância caiu muito e as demais espécies tornaram-se frequentes (Figura 2). Durante a segunda metade do período de floração de $S$. viscosa, também estavam disponíveis outras fontes florais de néctar relativamente abundantes e atrativas para as abelhas Xylocopa, no estrato herbáceo-sub-arbustivo nas dunas, destacando-se Cuphea brachiata Mart., Eriope blanchetii (Benth) Harley e Waltheria cinerescens A.St.-Hil.

A grande maioria das abelhas de porte médio ou grande apresentou comportamento legítimo de visita às flores de $S$. viscosa: pousavam na ala, projetando a cabeça para o interior da flor a fim de acessar o néctar na base da corola. Nesta atividade, acionavam a quilha, que

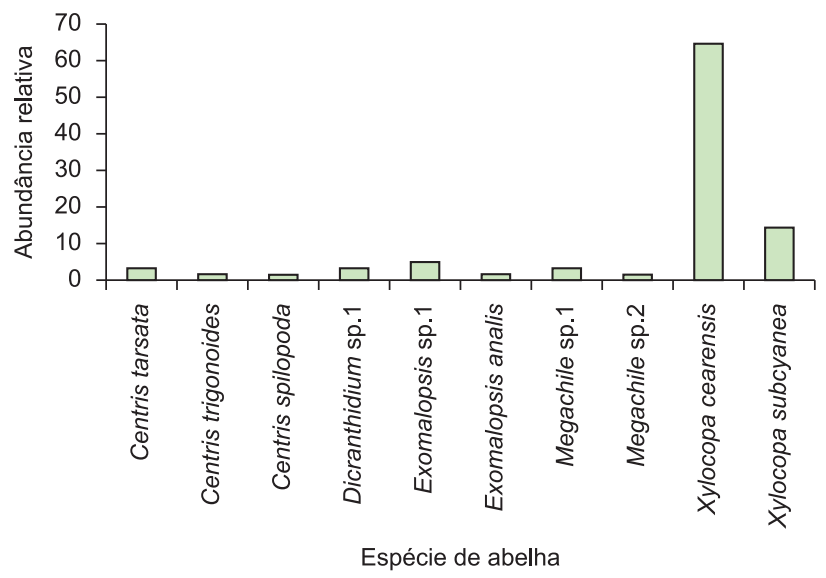

Figura 1. Abundância relativa das abelhas coletadas nas flores de Stylosanthes viscosa Sw., nas dunas urbanas de Salvador, Bahia.

Figure 1. Relative abundance of bees collected in flowers of Stylosanthes viscosa Sw., in urban sand dunes of Salvador, Bahia.

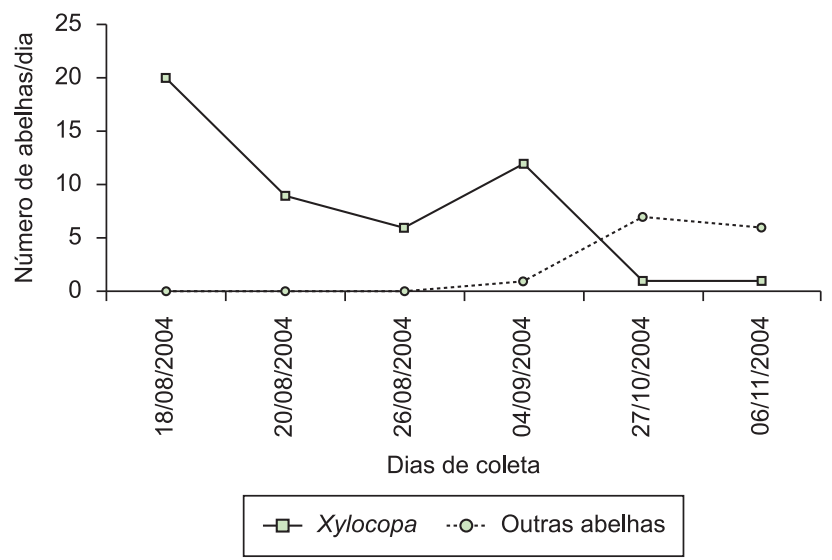

Figura 2. Variação temporal na abundância de abelhas Xylocopa e demais grupos de abelhas visitantes das flores de Stylosanthes viscosa Sw., nas dunas urbanas de Salvador, Bahia.

Figure 2. Temporal variation in abundance of Xylocopa bees and others bees visiting the flowers of Stylosanthes viscosa Sw., in urban sand dunes of Salvador, Bahia.

voltava à posição inicial após deixarem a flor. Entretanto, a visita das abelhas Xylocopa foi diferenciada e, aparentemente, incompatível com o mecanismo elaborado de polinização: pousavam sobre a flor em qualquer posição, prendendo-se à pequena inflorescência e, com seu grande corpo, acabavam deslocando para baixo toda a diminuta quilha. Como consequência, a quilha não voltava mais à posição inicial, deixando expostos o tubo estaminal e o estigma. Essas flores com o mecanismo de quilha inutilizado provavelmente não poderiam mais ser polinizadas por outras abelhas. Ainda assim, as abelhas Xylocopa tocavam as anteras e o estigma durante a visitação, condição básica para aquisição e transferência de pólen entre flores.

\section{Rotas de vôo das abelhas X. cearensis nas manchas de S. viscosa}

Nas rotas de vôo de $X$. cearensis, a distribuição de frequência das distâncias entre flores sucessivas apresentou forte concentração à direita da classe central (Figura 3). De um total de 82 vôos entre flores sucessivas, apenas $8,5 \%$ aconteceram entre flores a menos de um metro de distância. Distâncias entre um e dois metros foram mais 

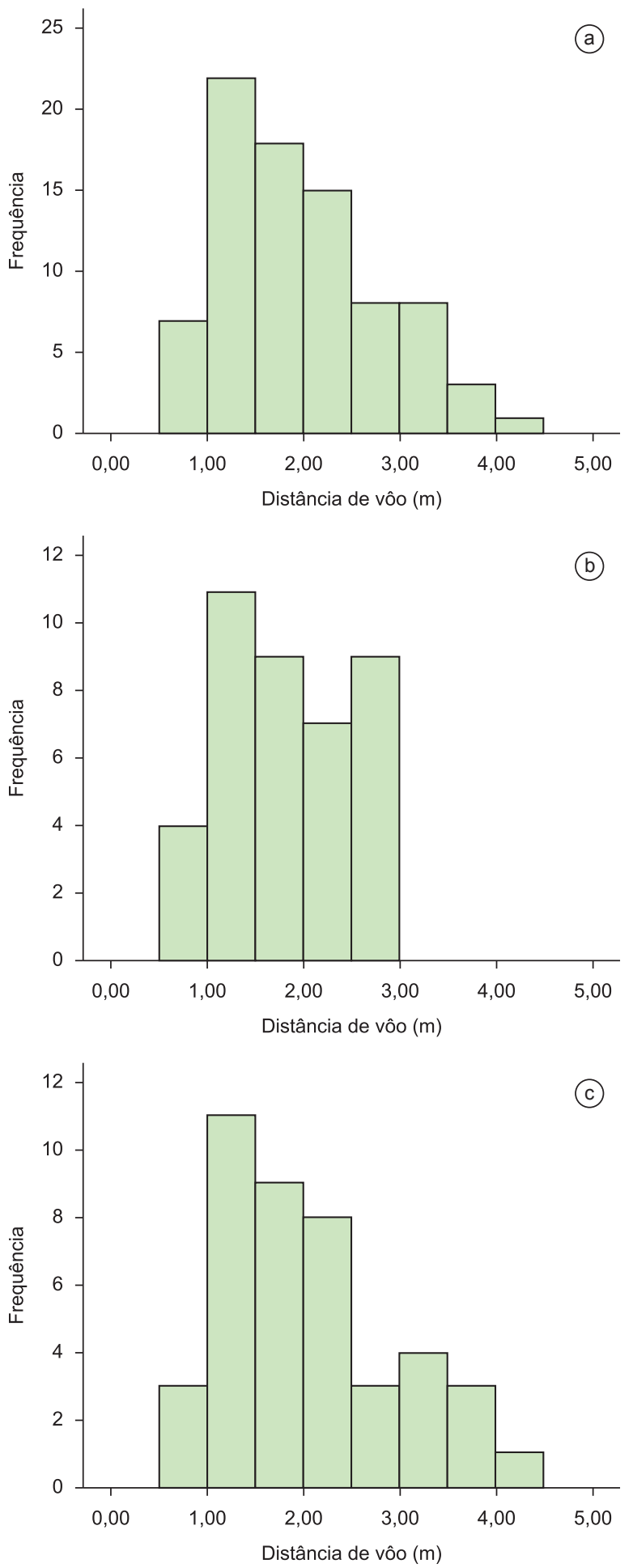

Figura 3. Distribuição de frequência das distâncias de vôo entre flores das abelhas Xylocopa (Neoxylocopa) cearensis forrageando em flores de Stylosanthes viscosa Sw., nas dunas urbanas de Salvador, BA. a) Todas as rotas; b) Rotas do dia 01/09/2004 (maior densidade de flores: 21 flores. $\mathrm{m}^{-2}$ ); c) Rotas do dia 09/09/2004 (menor densidade de flores: 5 flores.m ${ }^{-2}$ ).

Figure 3. Frequency distribution of interfloral flight distances for Xylocopa (Neoxylocopa) cearensis foraging at flowers of Stylosanthes viscosa Sw., in urban sand dunes of Salvador, BA. a) All the routes; b) Routes on 09/01/2004 (higher density of flowers: 21 flowers.m ${ }^{-2}$ ); c) Routes on 09/09/2004 (lower density of flowers: 5 flowers. $\mathrm{m}^{-2}$ ). frequentes, contabilizando 48,8\% dos casos, seguindo-se distâncias entre dois e três metros $(28 \%)$. Vôos a distâncias acima de três metros foram pouco frequentes $(14,6 \%)$. Assim, as abelhas evitaram vôos muito longos, mas não voaram com tanta frequência a distâncias tão curtas quanto seria possível, dada a densidade floral nas manchas: por exemplo, 0,15 a 0,7 m entre flores, entre a menor (5 flores. $\mathrm{m}^{-2}$ ) e a maior densidade ( 21 flores. $\mathrm{m}^{-2}$ ) amostradas.

Com alta frequência de ângulos pequenos de mudança de direção nas rotas de vôo (Figura 4), as abelhas $X$. cearensis moveram-se rapidamente através das manchas de flores. Poucas rotas apresentaram forte sinuosidade, com frequência relativa alta de ângulos ao redor de $90^{\circ}$, resultando praticamente na volta da abelha ao ponto de chegada à mancha. $\mathrm{O}$ número de flores visitadas a cada rota variou entre oito e 19, com média de 13,0 \pm 4,27 ( $\mathrm{N}=7)$, e aparentemente não houve relação entre número de passos (ou número de flores) numa rota e distâncias de vôo entre flores.

A variação na densidade floral de $S$. viscosa nas manchas foi significativa entre os dois períodos de análise das rotas de vôo ( $\mathrm{F}=7,154, \mathrm{p}=0,037, \mathrm{~N}=4)$, ainda assim não resultou em variação significativa nas distâncias de vôo $(\mathrm{F}=1,598, \mathrm{p}=0,21, \mathrm{~N}=40)$, nem nos ângulos médios de vôo das abelhas $X$. cearensis $(\mathrm{F}=1,695$, $\mathrm{p}=0,197, \mathrm{~N}=37$ ). Considerando a média e desvio padrão das distâncias de vôo por rota, nos dois períodos (média do período $1=1,81 \pm 0,19 \mathrm{~m}$; média do período $2=2,04 \pm 0,26 \mathrm{~m}$ ), também se conclui que não houve diferenças significativas (média: $U=3,0$, $\mathrm{p}=0,40, \mathrm{~N}=4$; desvio padrão: $\mathrm{U}=3,0, \mathrm{p}=0,40, \mathrm{~N}=4$ ).

\section{Discussão}

\section{Sistema de polinização e sistema reprodutivo}

O arrasto e exposição do pólen das anteras férteis por anteras secundárias observado em Stylosanthes viscosa Sw. ocorre em outras espécies do mesmo gênero (p.ex., Stylosanthes gracilis H.B.K. e Stylosanthes guianensis (Aubl.) Sw.) e é conhecido como mecanismo de êmbolo (Pereira-Noronha et al. 1982). Quando uma abelha aciona o sistema, o pólen deslocado para a porção distal pelas anteras secundárias é então empurrado através do orifício na extremidade da quilha tubular. Entretanto, não há apresentação secundária de pólen, isto é, a captura e disponibilização do pólen aos polinizadores por outro órgão floral (além das próprias anteras), que, via de regra, visa evitar a autopolinização (p.ex., Endress 1994). Pereira-Noronha et al. (1982) também afirmam que nas flores com mecanismo de êmbolo de Stylosanthes, a autopolinização (facilitada) sempre ocorre a cada visita das abelhas. Corroborando essa generalização, as flores de $S$. viscosa apresentaram níveis máximos de autopolinização autônoma (sem necessidade de visitante) e, consequentemente, de autofertilização. Através de análises de variabilidade genética, Barros et al. (2005) estimaram que a taxa de polinização cruzada em espécies de Stylosanthes é baixa, da ordem de 2 a $6 \%$, enquanto a autopolinização e autofertilização (auto-compatibilidade) são os mecanismos mais comuns de formação de sementes.

A inutilização da quilha de $S$. viscosa por Xylocopa Latreille, 1802 não compromete a autopolinização (autônoma ou facilitada), mas coloca em dúvida a eficiência dessas grandes abelhas na polinização cruzada. As flores danificadas teriam poucas chances de polinização cruzada, mesmo que fossem visitadas posteriormente por outras abelhas robustas. Pereira-Noronha et al. (1982) registraram efeito similar da visita das abelhas grandes Bombus atractus Franklin, 1913 às flores de Stylosanhtes gracilis e S. guianensis no Cerrado. Deve ser ressaltado que o dano causado por Xylocopa às flores de $S$. viscosa não resulta de comportamento destrutivo ativo, como se observa nos casos de roubadores de néctar ou pólen (p.ex., Inouye 

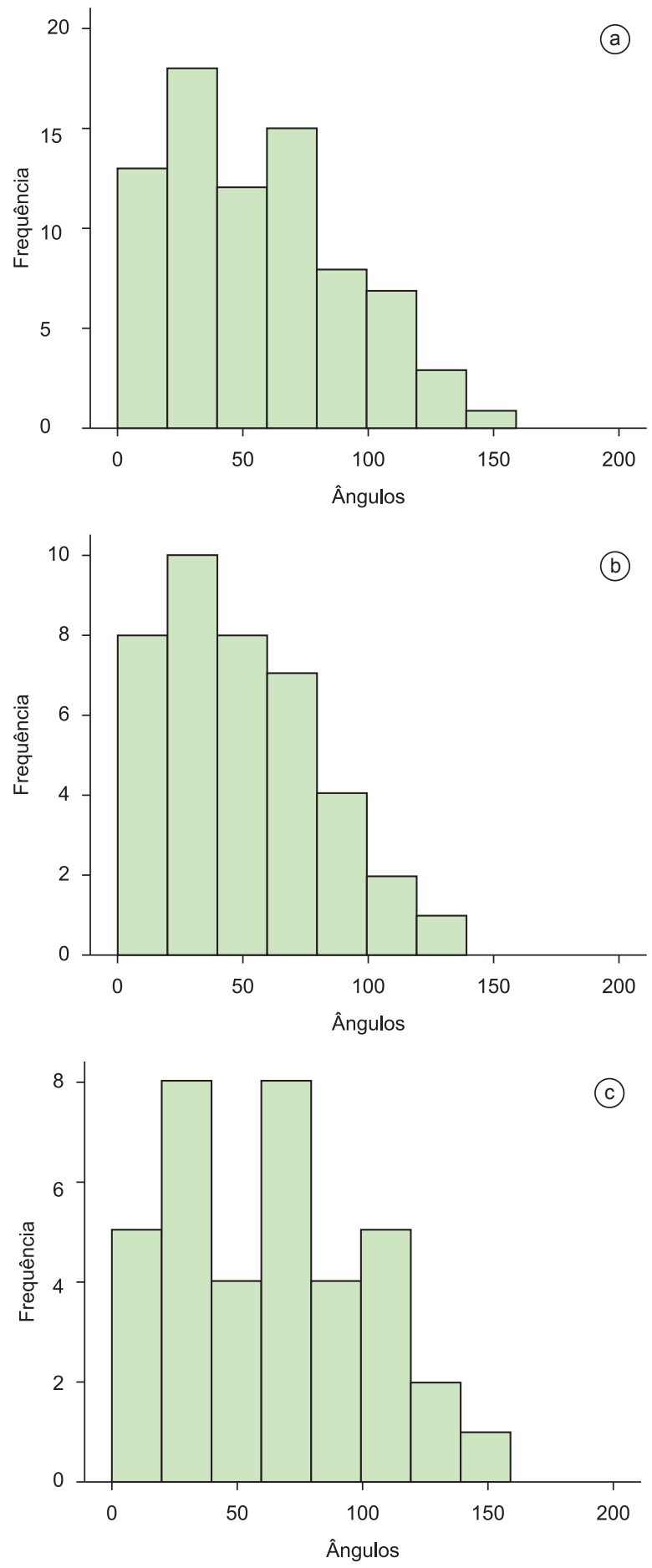

Figura 4. Distribuição de frequência de mudanças de direção (ângulos) nas rotas de forrageio das abelhas Xylocopa (Neoxylocopa) cearensis, entre flores consecutivas de Stylosanthes viscosa Sw., nas dunas urbanas de Salvador, BA. a) Todas as rotas; b) Rotas do dia 01/09/2004 (alta densidade de flores: 21 flores.m $^{-2}$ ); c) Rotas do dia 09/09/2004 (baixa densidade de flores: 5 flores. $\mathrm{m}^{-2}$ ).

Figure 4. Frequency distributions of changes in direction (angles) in foraging routes of Xylocopa (Neoxylocopa) cearensis bees between consecutive flowers of Stylosanthes viscosa Sw., in urban sand dunes of Salvador, BA. a) All the routes; b) Routes on 09/01/2004 (high density of flowers: 21 flowers. ${ }^{-2}$ ); c) Routes on 09/09/2004 (low density of flowers: 5 flowers. $m^{-2}$ ).
1980), mas sim, do forte contraste de tamanhos: $X$. cearensis tem cerca de $20 \mathrm{~mm}(\overline{\mathrm{x}}=19,4 \pm 1,16 ; \mathrm{N}=5)$ e as peças distendidas da quilha de $S$. viscosa têm menos de $5 \mathrm{~mm}(\overline{\mathrm{x}}=4,66 \pm 0,41 ; \mathrm{N}=5)$. Via de regra, a visita floral é legítima, mas seu resultado aparente não condiz com o sofisticado mecanismo da quilha.

Não se pode descartar a participação direta de Xylocopa na polinização cruzada de $S$. viscosa, ainda que implique em retornos baixos para a planta (baixa eficiência e altos custos), pois contatam as estruturas férteis e exibem alta constância floral dentro de uma mancha. Este último comportamento de abelhas Xylocopa também foi registrado em rotas de vôo dentro de manchas e entre manchas de Crotalaria retusa L., na região (Jacobi et al. 2005).

A oscilação temporal na frequência de Xylocopa em relação a outros grupos de abelhas nas manchas de $S$. viscosa deve ser desencadeada pela variação temporal na oferta de fontes de néctar nas dunas. Ainda durante a floração plena de $S$. viscosa (outubro), as abelhas Xylocopa passam a visitar com mais frequência outras fontes de néctar abundantes no estrato herbáceo-arbustivo das dunas, como Cuphea flava Spreng e Waltheria cinerescens A.St.-Hil., particularmente atrativas para essas abelhas maiores (Costa et al. 2002, Pigozzo et al. 2007). Ao contrário, os demais grupos de abelhas (p.ex., Centris, Exomalopsis, Megachile) provavelmente evitam S. viscosa apenas quando está sendo intensamente visitada pelas grandes abelhas Xylocopa, que demandam muito néctar (competição por exploração). Esta variação temporal também deve ter como consequência a alteração na taxa de polinização cruzada em relação à autopolinização das flores de S. viscosa, considerando particularmente a mudança esperada na frequência de flores com as quilhas danificadas.

\subsection{Uma rota evolutiva para a autopolinização em S. viscosa}

Dada a elevada especialização da flor de quilha e ao seu caráter essencialmente melitófilo (Westerkamp 1996), a autopolinização deveria ser vista como uma condição derivada em Stylosanthes. Neste caso, argumentamos que a rota evolutiva provável deriva da polinização cruzada, passando pela autopolinização facilitada por abelhas, chegando até a autopolinização autônoma, com o elaborado mecanismo de êmbolo. A ocorrência simultânea de autopolinização autônoma e facilitada aponta na direção da hipótese de segurança reprodutiva (Schoen et al. 1997). Entretanto, como raramente mais de uma flor está receptiva num mesmo indivíduo, a autopolinização facilitada está dissociada da geitonogamia, e isto aponta na direção da hipótese de seleção automática. Além disso, graças ao mecanismo de êmbolo, a autopolinização autônoma em $S$. viscosa tem provavelmente a mesma eficiência da autopolinização facilitada por abelhas.

De acordo com a hipótese de seleção automática (Schoen et al. 1997), em uma população com polinização cruzada estabelecida, um alelo mutante para autopolinização teria vantagens simplesmente por causa do desvio favorável de transmissão para a próxima geração (dose dupla com a autofertilização e uma terceira dose com a fertilização cruzada). Já a hipótese de segurança reprodutiva tem como premissa a depreciação de serviços de polinizadores (déficit ou baixa qualidade), especialmente na polinização cruzada (Harder \& Barrett 1996). Há evidências locais e regionais de que $S$. viscosa tem relação ecológica estreita (frequente no espaço e no tempo) com abelhas robustas de muitas espécies (p.ex., Viana et al. 2002, este estudo). Portanto, dada a oferta previsível de polinizadores, fica principalmente sustentada a premissa básica da seleção automática: a transferência de pólen mediada por um vetor é condição necessária para que ocorra o desvio favorável de transmissão do alelo (terceira dose) associado ao caráter que promove a autopolinização (Schoen et al. 1997).

Um caráter especial da flor que promovesse a autopolinização autônoma em Stylosanthes, no caso o êmbolo, contribuiria para elevar 
a produção de sementes e o valor adaptativo, se o resultado da visita de Xylocopa fosse a redução na taxa de polinização cruzada, também com aumento dos custos de atração (alto consumo de néctar, p.ex.). Como a quilha é acionada de maneira efetiva por Xylocopa, o mecanismo de êmbolo assegura a autopolinização facilitada. Entretanto, a autopolinização facilitada reduziria a disponibilidade de óvulos para fertilização cruzada, quando outras abelhas fossem temporariamente mais abundantes nas flores do que Xylocopa. Isto contraria a premissa básica da hipótese de segurança reprodutiva de que a autopolinização traz vantagens apenas quando assegura a fertilização de óvulos ainda não fecundados pela polinização cruzada.

Portanto, não deve ser o déficit de polinizadores, mas a oscilação temporal na qualidade da polinização (ora promovendo a polinização cruzada, ora a autopolinização) que explica a autopolinização autônoma em $S$. viscosa. Como a taxa de polinização cruzada oscila ao longo da floração, dependendo do grupo dominante de polinizadores (Xylocopa ou outras abelhas robustas), os riscos de perda de valor adaptativo do caráter (êmbolo) devido ao endo-cruzamento também estariam amenizados nas populações locais, a cada período reprodutivo.

\section{Restrições de forrageio nas manchas de S. viscosa e rotas de vôo de X. cearensis}

$\mathrm{O}$ ambiente de dunas tropicais demanda muita energia também para termo-regulação, de modo que o tamanho reduzido da flor de $S$. viscosa aliado à baixa densidade floral devem impor restrições mais severas sobre o forrageio das grandes abelhas $X$. cearensis. Nas manchas "bidimensionais" observou-se que essas abelhas realizavam regularmente rotas de vôo, resposta que deve incrementar a eficiência de visita às flores e obtenção de néctar. Por outro lado, quando outras fontes florais abundantes estavam disponíveis nas dunas, como referido acima, essas abelhas depreciaram a oferta de néctar nas flores de $S$. viscosa: evitaram as manchas floridas desta espécie, ainda muito atrativas para as demais abelhas robustas.

De acordo com a teoria de forrageio ótimo, os animais podem responder mais rapidamente à variação na oferta relativa de um recurso particular quando investem tempo explorando outras manchas de recursos simultaneamente (Pyke 1984). Por exemplo, as abelhas Apis e Bombus apresentam especialização temporal e demonstram habilidade de responder de maneira eficiente às variações na qualidade relativa de várias fontes, que monitoram simultaneamente (Hassell \& Southwood 1978, Howe \& Westley 1988). As abelhas Xylocopa apresentam alta constância floral dentro de cada mancha de $S$. viscosa, onde as plantas estão espacialmente muito concentradas. Por outro lado, como as manchas são discretas e estão amplamente dispersas nas dunas, também é muito provável que monitorem outras fontes florais de néctar no movimento entre manchas floridas.

As evidências sustentam que $X$. cearensis é capaz de aumentar a eficiência de forrageio de néctar em rotas de vôo através das manchas floridas bidimensionais de $S$. viscosa, ajustando a direção e as distâncias de vôo entre flores, mantendo pouco variável o número de passos mesmo com grande variação na densidade floral nas manchas.

A cauda mais longa à direita da curva de distribuição de frequência de distâncias de vôo de $X$. cearensis entre flores de S. viscosa também foi observada durante o registro do forrageio nas flores de Waltheria cinerescens A.St.Hil. (Costa et al. 2002) e Cuphea brachiata Koehne (Pigozzo et al. 2007). Concluímos que esse é um típico padrão de resposta a retornos (benefícios) decrescentes, quando os recursos estão atingindo limites críticos em relação aos custos de movimentação do forrageador (vôos muito longos em relação à oferta de néctar).

Os vôos de $X$. cearensis entre flores de $S$. viscosa ficaram concentrados em distâncias medianas (1-2 m), em relação à densidade floral, indicando que as abelhas também evitam vôos muito curtos numa mancha $(<1 \mathrm{~m})$, provavelmente por dois motivos: 1$)$ pequenas diferenças na distância de vôo entre uma flor e outra não alteram significativamente os custos de deslocamento porque, nestes casos, o maior gasto se concentra no momento de alçar o vôo (sair da inércia); 2) os vôos curtos demais aumentam os riscos de re-visitação de flores, que, neste caso, já oferecem níveis criticamente baixos de recursos por área de mancha florida (volume pequeno de néctar em flores pequenas e com baixa densidade).

A teoria da otimização prevê também ajustes nas distâncias médias de vôo e na sua variância, em resposta à variação na densidade floral (Waddington 1980). Pigozzo et al. (2007) observaram menor frequência de vôos curtos de $X$. cearensis quando forrageando em manchas com menor densidade floral de Cuphea brachiata nas dunas, entretanto não avaliaram a significância dessa variação. Por outro lado, essa espécie de abelha não respondeu às diferenças significativas de densidades florais de $S$. viscosa. Neste último caso, fica evidenciado que a variação na distância de vôo de $X$. cearensis entre flores não é uma função linear da densidade floral, ou seja, a abelha não responde à variação gradual na densidade de flores mas sim a limiares críticos na oferta de recursos (néctar) por área de forrageio (média e/ou variação entre flores).

A habilidade e/ou decisão de manter a direção nas rotas de forrageio observada em $X$. cearensis é um comportamento compartilhado com outras espécies de Xylocopa (Costa et al. 2002, Jacobi et al. 2005, Pigozzo et al. 2007). Este tipo de movimentação direcional também é compatível com a hipótese de otimização do forrageio, na medida em que contribui para reduzir as chances da abelha revisitar uma mesma flor (Waddington 1980, Pyke 1984). Em contrapartida, ângulos grandes de mudança de direção nas rotas predispõem essas abelhas à revisitação (Pigozzo et al. 2007) e isto de fato pode levar a ganhos líquidos menores (Cartar \& Real 1997).

Com flores diminutas e densidade floral muito baixa nas dunas, o néctar de $S$. viscosa está pulverizado por uma ampla superfície das manchas de $S$. viscosa e isto deveria desestimular principalmente os grandes consumidores, como Xylocopa. Entretanto, a distribuição bidimensional das flores em grandes manchas floridas também parece oferecer condições para redução dos custos de forrageio por essas abelhas que fazem rotas de vôo. Por exemplo, rotas direcionais de forrageio em Xylocopa (p.ex., Costa et al. 2002, Jacobi et al. 2005, Pigozzo et al. 2007) têm sido frequentemente observadas quando essas abelhas coletam recursos em flores de herbáceas com distribuição agregada em grandes manchas discretas.

\section{Conclusões}

Nesta relação paradoxal, as populações de $S$. viscosa poderiam estar usando estratégias reprodutivas alternativas ao longo da floração nas dunas tropicais: produção de sementes com maior variabilidade quando há boa oferta de abelhas robustas (mas não Xylocopa) e maior produção de sementes autogâmicas, principalmente quando $X y$ locopa é dominante nas manchas. A autopolinização e autocompatibilidade de $S$. viscosa não se configuram como solução para lidar com escassez ou deficiência dos serviços dos seus potenciais polinizadores, que são principalmente abelhas de médio a grande porte abundantes nas dunas tropicais. Ao contrário, o tamanho diminuto desta flor de quilha, a baixa densidade floral e a autopolinização (autônoma ou facilitada, associada ao mecanismo de êmbolo) configuram-se melhor como ajustes coordenados com uma estratégia de desestímulo à visitação pelas maiores abelhas, como X. cearensis. Assim, a hipótese de segurança reprodutiva oferece explicação menos satisfatória do que a hipótese de seleção automática para os sistemas de polinização e reprodutivo de $S$. viscosa.

Apesar do forte contraste de tamanhos e das condições aparentemente adversas de forrageio de néctar nas flores de $S$. viscosa 
nas dunas tropicais, o desestímulo às abelhas Xylocopa funciona apenas parcialmente, por causa da predisposição dessas abelhas para traçar rotas de vôo em manchas florais bidimensionais, melhorando a eficiência global de forrageio. Ainda assim, do ponto de vista das grandes abelhas $X$. cearensis, o néctar de $S$. viscosa deve estar tão disperso no espaço, que o forrageio "otimizado" nas rotas de vôo deve ser o "melhor possível de um mau negócio". Por isso, sempre que possível, depreciam as manchas de $S$. viscosa em favor de outras fontes de néctar nas dunas.

Nas dunas costeiras tropicais, as flores diminutas de $S$. viscosa provavelmente expressam uma fase de ruptura incompleta na melitofilia (desestímulo à visitação pelas grandes abelhas Xylocopa), atrelada à autopolinização autônoma, assegurada pelo mecanismo de êmbolo das anteras.

\section{Agradecimentos}

Ao PIBIC/UFBA e à FAPESB, pela bolsa de Iniciação Científica concedida. A Mariana Laly Silva Batista pela ajuda nas coletas de campo. À Dra. Claudia Maria Jacobi (Universidade Federal de Minas Gerais) pelas valiosas contribuições.

\section{Referências Bibliográficas}

ALCÂNTARA, P.B., DUARTE, K.M.R. \& MATTOS, W.T. 2007. Novas alternativas para germoplasma forrageiro - Leguminosas. http://www. infobibos.com/Artigos/2007_2/leguminosas/index.htm (último acesso em: 31/07/2008).

BARROS, A.M., FALEIRO, F.G., KARIA, C.T., SHIRATSUCHI, L.S., ANDRADE, R.P. \& LOPES, G.K.B. 2005. Variabilidade genética e ecológica de Stylosanthes macrocephala determinadas por RAPD e SIG. Pesq. Agropec. Bras. 40:899-909.

CARTAR, R.V. \& REAL, L.A. 1997. Habitat structure and animal movement: the behavior of bumble bees in uniform and random spatial resource distributions. Oecologia 112:430-434.

COSTA, C.B.N., COSTA, J.A.S., RODARTE, A.T.A. \& JACOBI, C.M. 2002. Comportamento de forrageio de Xylocopa (Neoxylocopa) cearensis Ducke, 1910 (Apidae) em Waltheria cinerascens A.S.t.Hil. (Sterculiaceae) em dunas costeiras (APA do Abaeté, Salvador, Bahia, Brasil). Sitientibus 2:23-28.

ENDRESS, P.K. 1994. Diversity and evolutionary biology of the tropical flowers. Cambridge University Press, Cambridge.

FRANKIE, G.W., HABER, W.A., OPLER, P.A. \& BAWA, K.S. 1983. Characteristics and organization of the large bee pollination system in the Costa Rican dry forest. In Experimental Pollination Biology (C.E. Jones \& R.J. Little, eds.). Scientific and Academic Editions, New York, p. 411-447.

GERLING, D., VELTHUIS, H.H.W. \& HEFETZ, A. 1989. Bionomics of the large carpenter bees of the genus Xylocopa. Annu. Rev. Entomol. 34:163-190.

GOTTSBERGER, G., CAMARGO, J.M.F. \& SILBERBAUERGOTTSBERGER, I. 1988. A bee-pollinated tropical community: The beach dune vegetation of ilha de São Luís, Maranhão, Brazil. Bot. Jahrb. Syst. 109(4):469-500.

HARDER, L.D. \& BARRETT, S.C.H. 1996. Pollen dispersal and mating patterns in animal pollinated plants. In Floral Biology: Studies on Floral Evolution in Animal-pollinated Plants (D.G. Lloyd \& S.C. Barrett, eds.). Chapman and Hall, p. 140-190.

HASSELL, M.P. \& SOUTHWOOD, T.R.E. 1978. Foraging strategies of insects. Ann. Rev. Ecol. Syst. 9:75-98.

HOWE, H.F. \& WESTLEY, L.C. 1988. Ecological relationships of plants and animals. Oxford University Press, New York.

HURD Jr., P.D. \& MOURE, J.S. 1963. A classification of the large carpenter bees (Xylocopini) (Hymenoptera, Apoidea). Univ. Calif. Publ. Entomol. 29:1-365.

INOUYE, D.W. 1980. The terminology of floral larceny. Ecology 61(5):1251-1253.
JACOBI, C.M., RAMALHO, M., \& SILVA, M. 2005. Pollination biology of the exotic rattleweed Crotalaria retusa L. (Fabaceae) in NE Brazil. Biotropica 37:356-362.

JANZEN, D.H. 1983. Insects. Introduction. In Costa Rican Natural History (D.H. Janzen, ed.). Chicago Univ. Press, p. 619-645.

MINCKLEY, R.L. 1998. A cladistic analysis and classification of the subgenera and genera of the large carpenter bees, tribe Xylocopini (Hymenoptera: Apidae). Sci. Pap. Nat. Hist. Mus. Univ. Kans. 9:1-47.

NUÑEZ, J.A. 2000. Foraging efficiency and survival of African honeybees in the tropics. In Anais do Encontro sobre Abelhas. Ribeirão Preto, p. 9-16.

PEREIRA, J.M. 2008. Utilização de leguminosas forrageiras na alimentação de bovinos. http://www.ceplac.gov.br/radar/Artigos/artigo29.htm (último acesso em 31/07/2008).

PEREIRA-NORONHA, M.R., GOTTSBERGER, I.S. \& GOTTSBERGER, G. 1982. Biologia floral de Stylosanthes (Fabaceae) no Cerrado de Botucatu, estado de São Paulo. Rev. Bras. Biol. 43:595-605.

PIGOZZO, C.M., NEVES, E.L., JACOBI, C.M. \& VIANA, B.F. 2007. Comportamento de forrageamento de Xylocopa (Neoxylocopa) cearensis Ducke (Hymenoptera: Apidae, Xylocopini) em uma população de Cuphea brachiata Koehne (Lythraceae). Neotrop. Entomol. 36:652-656.

PYKE, G.H. 1984. Optimal foraging theory: a critical review. Ann. Rev. Entomol. 15:523-75.

SACRAMENTO, A.C., ZICKEL, C.S. \& ALMEIDA JR, E.B. 2007 Aspectos florísticos da vegetação de restinga no litoral de Pernambuco. Rev. Árvore. 31:1121-1130.

SAWKINS, M.C., MAASS, B.L., PENGELLY, B.C., NEWBURY, H.J., FORD-LLOYD, B.V., MAXTED, N. \& SMITH, R. 2001. Geographical patterns of genetic variation in two species of Stylosanthes Sw. using amplified fragment length polymorphism. Mol. Ecol. 10:1947-1958.

SCHOEN, D.J., MORGAN, M.T. \& BATAILON, T. 1997. How does selfpollination evolve? Inferences from floral ecology and molecular genetic variation. In Plant life histories (J. Silvertown, M. Franco \& J.L. Harper, eds.). Cambridge University Press, Cambridge, p. 77-101.

SCHOENER, T.W. 1971. Theory of feeding strategies. Ann. Rev. Ecol. Syst. 2:369-404.

SEELEY, T.D. 1995. The wisdom of the hive. Harvard University Press, Cambridge.

SILVA, M.C.M. \& MARTINS, C.F. 1999. Flora apícola e relações tróficas de abelhas (Hymenoptera: Apoidea) em uma área de restinga (Praia de Intermares, Cabedelo - PB, Brasil). Principia 7:40-51.

STAPPEN, J.V., LOPEZ, U.G \& VOLCKAERT, G. 2002. Molecular evidence for the hybrid origin of a new endemic species of Stylosanthes Sw. (Fabaceae) from the Mexican Yucatán Peninsula. Bot. J. Linn. Soc. 140:1-13.

VAN DER PIJL, L. 1954. Xylocopa and flowers in the tropics. I-III. Proc. K. Ned. Akad. Wet. 57:413-562.

VIANA, B.F. \& KLEINERT, A.M.P. 2006. Structure of bee-flower system in the coastal sand dune of Abaeté, northeastern Brazil. Rev. Bras. Entomol. 50:53-63.

VIANA, B.F., KLEINERT, A.M.P. \& SILVA, F.O. 2002. Ecologia de Xylocopa (Neoxylocopa) cearensis (Hymenoptera, Anthophoridae) nas dunas litorâneas de Abaeté, Salvador, Bahia. Iheringia. 92:47-57.

VIANA, B.F., SILVA, F.O. \& KLEINERT, A.M.P. 2006. A flora apícola de uma área restrita de dunas litorâneas, Abaeté, Salvador, Bahia. Rev. Bras. Bot. 29:13-25.

WADDINGTON, K.D. 1980. Flight patterns of foraging bees relative to density of artificial flowers and distribution of nectar. Oecologia (Berl.). 44:199-204.

WESTERKAMP, C.H. 1996. Pollen in bee-flower relations. Bot. Acta. 109:325-332. 